Revista Brasileira de Agricultura Irrigada v.11, nº.7, p. 2010 - 2021, 2017

ISSN 1982-7679 (On-line)

Fortaleza, CE, INOVAGRI - http://www.inovagri.org.br

DOI: $10.7127 /$ rbai.v11n700670

Protocolo 670.17 - 26/04/2017 Aprovado em 17/09/2017

\title{
SUBSTRATOS E NÍVEIS DE REPOSIÇÃO DE ÁGUA NA PRODUÇÃO DE MUDAS DE MELÂNCIA
}

\begin{abstract}
Alex Serafim de Lima ${ }^{1}$, Jackson de Mesquita Alves ${ }^{2}$, Francisca Lacerda da Silva ${ }^{3}$, Jessica da Mota Santos ${ }^{4}$, Evandro Franklin de Mesquita ${ }^{5}$, Hugo Orlando Carvallo Guerra ${ }^{6}$
\end{abstract}

\begin{abstract}
RESUMO
A melancia é uma das hortaliças mais consumidas e produzidas no Brasil. Assim sendo, objetivou - se avaliar diferentes substratos e níveis de água disponíveis na produção de mudas de melancia. O experimento foi conduzido no período de junho a agosto de 2016, numa estufa agrícola, adotando-se o sistema DIC, com arranjo fatorial 7x2, sendo sete substratos $\mathrm{S}_{1}=100 \%$ solo, $S_{2}=75 \%$ solo $+25 \%$ esterco bovino; $S_{3}=75 \%$ solo $+25 \%$ húmus; $S_{4}=50 \%$ solo $+50 \%$ E. B.; $S_{5}=50 \%$ solo $+50 \%$ húmus; $S_{6}=25 \%$ solo $+75 \%$ E. B.; $S_{7}=25 \%$ solo $+75 \%$ húmus, e dois níveis de água no substrato: 50 e 100\% da água disponível do substrato, com 4 repetições, totalizando 56 unidades experimentais. As melhores mudas formaram - se nos substratos contendo $75 \%$ de matéria orgânica e $25 \%$ de solo, sendo o esterco bovino o substrato mais eficiente na retenção e uso da água em comparação aos húmus de minhoca. A redução de $100 \%$ para 50\% de água disponível no substrato reduziu a produção de mudas. As plantas submetidas a déficit hídrico (50\% água disponível no substrato) apresentaram melhor eficiência do uso da água em comparação com aquelas formadas com 100\% de água disponível.
\end{abstract}

Palavras-chaves: Citrulluslunatus, estresse hídrico, insumos orgânicos.

\section{SUBSTRATUS AND LEVELS OF WATER REPLACEMENT IN THE PRODUCTION OF WATER MELON SEEDLINGS}

\footnotetext{
${ }^{1}$ E-mail: alexcdf10@hotmail.com, Universidade Estadual da Paraíba (UEPB), Campus IV, Catolé do RochaPB.

${ }^{2}$ E-mail: jacksoncitogenetica@hotmail.com, Universidade Estadual da Paraíba (UEPB), Campus IV, Catolé do Rocha-PB.

${ }^{3}$ E-mail: franciscalacerdadasilva@hotmail.com, Universidade Estadual da Paraíba (UEPB), Campus IV, Catolé do Rocha-PB.

${ }^{4}$ E-mail: motta.jessica@ymail.com, Universidade Estadual da Paraíba (UEPB), Campus IV, Catolé do RochaPB.

${ }^{5}$ E-mail: elmesquita4@uepb.edu.br, Universidade Estadual da Paraíba (UEPB), Campus IV, Catolé do RochaPB.

${ }^{6}$ E-mail: hugo_carvallo@hotmail.com, Universidade Federal de Campina Grande (UFCG), Campina GrandePB.
} 


\begin{abstract}
Watermelon is one of the olerícolas most consumed and produced in Brazil. Considering this, objective toevaluate the effect of different substrates and available water levels for plants on the watermelon seeds production.The study was carried out from June to August 2016, in a greenhouse, using a completely randomized design with a 7x2 factorial arrangement, being seven substrates $\mathrm{S}_{1}=100 \%$ soil, $\mathrm{S}_{2}=75 \%$ Soil $+25 \%$ bovine manure); $\mathrm{S}_{3}=75 \%$ Soil $+25 \%$ humus; $\mathrm{S}_{4}=50 \%$ Soil $+50 \%$ bovine manure .; $\mathrm{S}_{5}=50 \%$ Soil $+50 \%$ humus; $\mathrm{S}_{6}=25 \%$ Soil + $75 \%$ bovine manure, $S_{7}=25 \%$ Soil $+75 \%$ humus, and two water levels in the substrate: 50 and $100 \%$ of available water in the substrate, with 4 replicates, totalizing 56 experimental units. The best seedlings were formed on the substrates containing $75 \%$ organic matter and $25 \%$ of soil, being the bovine manure more efficient in the retention and efficiency of water use in the substrate than the earthworm humus. The reduction of $100 \%$ to $50 \%$ available water in the substrate decreased the production of seedlings. The plants submitted to water deficit (50\% available water in the substrate) presented better efficiency of water use than those formed with $100 \%$ of available water.
\end{abstract}

Keywords: Citrulluslunatus, water stress, organic inputs.

\section{INTRODUÇÃO}

A melancia é uma planta herbácea, com ciclo anual que varia de 70 a 120 dias, de sistema radicular extenso, mas raso, com um predomínio de raízes nos primeiros $60 \mathrm{~cm}$ do solo, apresentando folhas profundamente lobadas. É uma planta monóica apresenta flores solitárias, pequenas e de coloração amarela que permanecem abertas durante menos de um dia. O fruto é um pepônio cujo peso varia entre $1 \mathrm{a} 25 \mathrm{~kg}$ e chega a $60 \mathrm{~cm}$ de comprimento. (ALVARENGA e RESENDE, 2002; FILGUEIRA, 2007).

A alta produtividade só é possível com o investimento, principalmente em novas tecnologias de produção de mudas e cultivo. A atividade de elaboração de mudas de melancieira ainda é um tema pouco explorado, dessa forma tornam-se necessárias metodologias que definam técnicas mais adequadas à produção através da seleção de melhores substratos, tamanho de recipiente, manejo de água, sementes, e etc., a fim de avaliar a relação custo-benefício (SCHMITZ et al., 2002; TOSTA et al., 2010;). Ressalta-se que, uma maior lucratividade dos negócios agrícolas passa pelo processo de redução dos custos de produção (GOMES JUNIOR et al., 2011; DUTRA et al., 2015).
A escolha do substrato é uma das etapas mais importantes na produção de mudas e deve levar em consideração as exigências nutricionais das espécies cultivadas. A escolha ideal influencia diretamente na qualidade das mesmas, uma vez que, as características físicas e químicas são determinantes na qualidade, afetando tanto o crescimento quanto a produção (MAGGIONI et al., 2014). Desta forma, o uso dos compostos orgânicos como substratos tornou-se uma alternativa factível, uma vez que na sua composição é usada matéria orgânica encontrada na propriedade, facilitando a acessibilidade e aproveitando melhor os resíduos orgânicos, sólidos e/ou líquidos, disponíveis.

As lâminas de irrigação ideais a serem aplicadas devem variar em função das exigências da cultura e das condições meteorológicas no local de produção. De maneira geral, as irrigações são realizadas com alta frequência e em quantidade superior à necessidade hídrica das plantas, provocando desperdício de água, além disso, o excesso hídrico pode causar perdas de mudas por patologias, em virtude da alta umidade no substrato, provocando o encarquilhamento e clorose das folhas e geotropismo negativo das raízes (ALFENAS et al., 2009). Outro fator importante a ser observado é que o excesso de 
água pode causar a lixiviação dos nutrientes presentes no substrato, (REGO et al., 2005).

Em contraparte, a escassez de água afeta drasticamente o metabolismo das plantas, induzindo o fechamento dos estômatos, a fim de evitar a perda de água por transpiração, o que acarreta a redução da atividade fotossintética e uma série de outros processos nos vegetais (TAIZ e ZEIGER, 2013).

Objetivou-se avaliar o efeito de substratos e níveis de água disponíveis na produção de mudas de melancia.

\section{MATERIAL E MÉTODOS}

O experimento foi conduzido no período de 22 de julho a 09 de agosto de 2016 em ambiente protegido (estufa) no Centro de Ciências Humanas e Agrárias - CCHA, Universidade Estadual da Paraíba, Campus IV, no setor experimental de agroecologia, no município de Catolé do Rocha - PB. O município está situado sob as coordenadas geográficas $06^{\circ} 20^{\prime}$ de latitude Sul, $37^{\circ} 44^{\prime}$ de longitude oeste de Greenwich e uma altitude de $272 \mathrm{~m}$.

O clima do município, de acordo com a classificação de Köppen, é do tipo BSh, ou seja, quente e seco do tipo estepe, caracterizado como semiárido quente, com duas estações distintas, uma chuvosa com precipitação irregular e outra sem precipitação. Com temperatura média mensal de $27{ }^{\circ} \mathrm{C}$. A temperatura interna média, máxima e mínima da estufa situa-se em torno de $34^{\circ} \mathrm{C}, 42^{\circ} \mathrm{C}$ e $19^{\circ} \mathrm{C}$, com umidade relativa do ar variando de $35 \%$ a $52 \%$ entre julho e agosto.

O delineamento utilizado foi o inteiramente casualizado, com arranjo fatorial $7 x 2$, sendo sete substratos $S_{1}=100 \%$ solo, $S_{2}=$ $75 \%$ solo $+25 \%$; E. B. (esterco bovino); $\mathrm{S}_{3}=$ $75 \%$ solo $+25 \%$ húmus; $\mathrm{S}_{4}=50 \%$ solo $+50 \%$ E. B.; $\mathrm{S}_{5}=50 \%$ solo $+50 \%$ húmus; $\mathrm{S}_{6}=25 \%$ solo $+75 \%$ E. B; S $_{7}=25 \%$ solo $+75 \%$ húmus, (Tabela 1) e dois níveis de água no solo (ADS): $\mathrm{N}_{1}=50 \%$ da água disponível no substrato (ADS) e $\mathrm{N}_{2}=100 \%$ de água disponível no substrato com 4 repetições, totalizando 56 unidades experimentais.

Para o preparo dos substratos foi utilizado um Neossolo Flúvico Eutrófico, solo predominante na região na microrregião de Catolé do Rocha (EMBRAPA, 2013). Após coletadas amostras de solo na camada superficial $(0-20 \mathrm{~cm})$, estas foram colocadas para secar ao ar, destorroadas e peneiradas com peneira com malha de $2 \mathrm{~mm}$, segundo metodologia propostas pela EMBRAPA (2011).

Tabela 1. Características químicas e físicas do Neossolo Flúvico Eutrófico utilizado no experimento.

\begin{tabular}{|c|c|c|c|}
\hline $\begin{array}{l}\text { Características Químicas } \\
\text { (Fertilidade) }\end{array}$ & Valor & Características Físicas & Valor \\
\hline $\mathrm{P}(\mathrm{H} 2 \mathrm{O})(1: 25)$ & 6,7 & Areia $\left(\mathrm{g} \mathrm{kg}^{-1}\right)$ & 640,00 \\
\hline Cálcio $\left(\mathrm{cmol}_{\mathrm{C}} \mathrm{dm}^{-3}\right)$ & 1,49 & Silte $\left(\mathrm{g} \mathrm{kg}^{-1}\right)$ & 206,00 \\
\hline Magnésio $\left(\mathrm{cmol}_{\mathrm{c}} \mathrm{dm}^{-3}\right)$ & 0,54 & Argila (g kg-1) & 154,00 \\
\hline Sódio $\left(\mathrm{cmol}_{\mathrm{C}} \mathrm{dm}^{-3}\right)$ & 0,10 & Classificação textural & $\begin{array}{l}\text { Franco } \\
\text { Arenoso }\end{array}$ \\
\hline Potássio $\left(\mathrm{cmol}_{c} \mathrm{dm}^{-3}\right)$ & 1,72 & Densidade global ( $\mathrm{g} \mathrm{dm}^{-3}$ ) & 1,54 \\
\hline Soma de bases (S) $\left(\mathrm{cmol}_{\mathrm{C}} \mathrm{dm}^{-3}\right)$ & 3,85 & Densidade das partículas $\left(\mathrm{g} \mathrm{dm}^{-3}\right)$ & 2,68 \\
\hline $\begin{array}{l}\text { Hidrogênio + Alumínio }\left(\mathrm{cmol}_{C} \mathrm{dm}^{-}\right. \\
\left.{ }^{-}\right)\end{array}$ & 0,00 & Porosidade total (\%) & 42,54 \\
\hline $\begin{array}{l}\text { Capacidade de troca de cátions } \\
\left(\mathrm{cmol}_{\mathrm{c}} \mathrm{dm}^{-3}\right)\end{array}$ & 3,85 & Capacidade de campo $\left(\mathrm{g} \mathrm{kg}^{-1}\right)$ & 146,9 \\
\hline Saturação por Bases (V \%) & $100 \%$ & Ponto de murcha Permanent $\left(\mathrm{g} \mathrm{kg}^{-1}\right)$ & 76,60 \\
\hline Carbonato de cálcio qualitativo & Ausente & Água disponível (g kg-1) & 70,3 \\
\hline Carbono orgânico (\%) & 0,67 & & \\
\hline Matéria orgânica (\%) & 1,2 & & \\
\hline Nitrogênio (\%) & 0,07 & & \\
\hline Fósforo assimilável (mg dm $\left.{ }^{-3}\right)$ & 16,83 & & \\
\hline
\end{tabular}


Ainda para o preparo do substrato foi utilizado esterco bovino curtido e húmus de minhoca, cuja caracterização química encontra-se na Tabela 2.

Tabela 2. Características químicas do esterco bovino e do húmus de minhoca, utilizados no experimento.

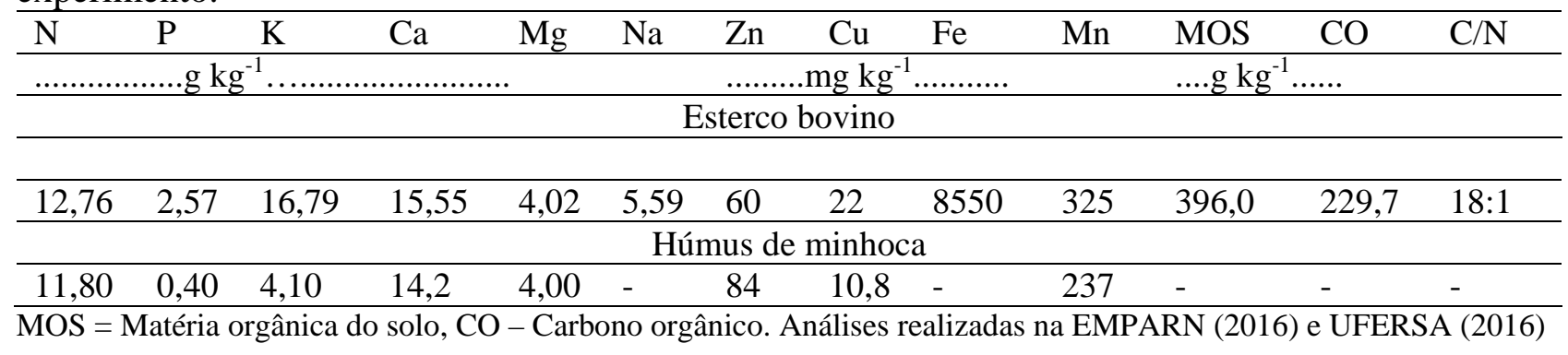

A semeadura foi realizada em copos plásticos de coloração preta com $7,2 \mathrm{~cm}$ de largura, $11,2 \mathrm{~cm}$ de altura e $1,0 \mathrm{~mm}$ de espessura com capacidade para $300 \mathrm{ml}$ de volume de substrato. A variedade utilizada foi a Crimson Sweet, com 96\% de germinação e 99\% de pureza, variedade amplamente difundida no Brasil, e principalmente na região Nordeste do país. A semeadura foi realizada colocando-se três sementes por recipiente. O desbaste das mudas foi feito aos 5 dias após a semeadura (DAS), quando as mudas estavam com um par de folhas definitivas, deixando a mais vigorosa por recipiente.

A irrigação das plantas foi realizada com um volume uniforme de água, em função da evapotranspiração medida no tratamento testemunha. O volume aplicado ( $V a$ ) por recipiente foi obtido pela diferença entre a média do peso do recipiente em condição de $100 \%$ da água disponível $\left(P_{c c}\right)$ e o peso médio dos recipientes na condição atual antes da irrigação. O peso do recipiente com solo a capacidade de campo $(100 \%$ da água disponível) foi determinado saturando-se o solo e submetendo à drenagem; quando o volume drenado era reduzido, os recipientes eram pesados.

Como a água da região semiárida apresenta salinidade variável, que muitas vezes afetam o crescimento das plantas, a água utilizada na irrigação foi analisada no Laboratório de Irrigação e Salinidade (LIS) do Centro de Tecnologia e Recursos Naturais da Universidade Federal de Campina Grande (UFCG). As características químicas da água são apresentadas na Tabela 3.

Tabela 3. Características químicas da água utilizada para irrigação.

\begin{tabular}{|c|c|c|c|c|c|c|c|c|c|c|c|}
\hline $\mathrm{pH}$ & $\mathrm{CE}_{25^{\circ} \mathrm{C}}$ & $\mathrm{Ca}^{+2}$ & $\mathrm{Mg}^{+2}$ & $\mathrm{Na}^{+1}$ & $\mathrm{~K}^{+1}$ & $\mathrm{Cl}^{-1}$ & $\mathrm{CO}_{3}{ }^{2-}$ & $\mathrm{HCO}_{3}{ }^{-}$ & $\mathrm{SO}_{4}{ }^{2-}$ & $\begin{array}{l}\text { PST } \\
\end{array}$ & RAS \\
\hline & $\mathrm{dS} \mathrm{m}^{-1}$ & & & & $\mathrm{l}_{\mathrm{C}} \mathrm{L}^{-1} \ldots$ & & & & & - & - \\
\hline 6, & 1,10 & 0,84 & 0,35 & 6,83 & 0,64 & 6,30 & 1,30 & 8,60 & 0,20 & 10,55 & 8,85 \\
\hline
\end{tabular}

C.E.: Condutividade Elétrica a $25^{\circ}$ C, RAS: Relação de Adsorção de Sódio, PST: Percentagem de Sódio Trocável, cla= classificação.

Aos 20 dias após a semeadura (DAS), no final do experimento, as plantas de melancieira foram avaliadas quanto à altura da planta e diâmetro do caule. A altura da planta foi medida do colo à base da folha mais jovem da planta com régua graduada em centímetros. $\mathrm{O}$ diâmetro do caule foi determinado com um paquímetro, com as leituras sendo efetuadas a
$1 \mathrm{~cm}$ de altura na região do colo de cada planta, nos mesmos períodos estabelecidos para mensuração da altura de plantas. Posteriormente as biometrias, o material vegetal colhido foi separado em raízes, caules, folhas, acondicionado em sacos de papel e seco em estufa de circulação de ar a temperatura de $60^{\circ} \mathrm{C}$ até atingir peso constante e pesados numa 
balança com precisão de 0,0001 g. De posse desses dados, obteve a massa seca da parte aérea (Folhas + Caule) (MSPA). A obtenção da massa seca total (MST) se deu através da soma dos pesos de seca da parte aérea e raiz.

O índice de qualidade de Dickson (IQD) é um indicador da qualidade de mudas, e foi determinado em função da altura da planta (AP), diâmetro caulinar (DC), massa seca da parte aérea (MSPA) e massa seca da raíz (MSR), por meio da seguinte fórmula (DICKSON et al., 1960):

$$
\frac{M S T(g)}{\frac{A P(\mathrm{~cm})}{D C(\mathrm{~mm})}+\frac{M S P A(\mathrm{~g})}{M S R(g)}}
$$

A eficiência de uso da água (EUA) foi obtida pelo quociente entre a matéria seca total e o volume total de água aplicado durante o experimento:

$$
E U A=\frac{M S T(g)}{\text { Consumo de água }(\mathrm{ml})}
$$

Os dados foram submetidos à análise de variância, ao nível de significância de 5\%. Com base na significância dos dados aplicou-se o teste de Tukey, a $5 \%$ de probabilidade, utilizando o aplicativo SISVAR (FERREIRA, 2011).

\section{RESULTADOS E DISCUSSÃO}

De acordo com a Tabela 4, houve efeito significativo $(\mathrm{p}<0,01)$ da interação substratos versus níveis de água para a fitomassa seca, eficiência do uso da água e o Dickson (IQD) na produção de mudas de melancia, indicando dependência dos fatores.

Tabela 4. Análise de variância referente à Altura da planta (AP), diâmetro caulinar (DC), peso seco da parte aérea (PSPA), peso seco total (PST), eficiência do uso da água (EUA) e índice de qualidade de Dickson (IQD) na produção de mudas de melancia sob substratos e níveis de água disponíveis no

\begin{tabular}{|c|c|c|c|c|c|c|c|}
\hline \multirow[t]{2}{*}{ Fonte de variação } & \multirow{2}{*}{ GL } & \multicolumn{6}{|c|}{ Significância dos quadrados médios } \\
\hline & & AP & DC & PSPA & PST & IQD & EUA. \\
\hline Substratos & 6 & & & . & & & \\
\hline Níveis de água & 1 & ns & ** & ** & ** & ns & ** \\
\hline Interação & 6 & ${ }^{* *}$ & ** & ** & ** & ** & ** \\
\hline Resíduo & 42 & 0,07 & 0,14 & 0,0014 & 0,0027 & 0,0009 & 0,009 \\
\hline CV (\%) & & 6,54 & 9,43 & 9,82 & 6,76 & 13,85 & 7,58 \\
\hline \multirow{2}{*}{ Média Geral } & & $\mathrm{cm}$ & $\mathrm{mm}$ & & $\ldots \ldots \ldots$ & $\ldots \ldots \ldots$ & $\mathrm{mL} \mathrm{g}^{-1}$ \\
\hline & & 3,91 & 3,99 & 0,39 & 0,60 & 0,21 & 1,25 \\
\hline
\end{tabular}
solo.

GL - Grau de liberdade; significativo a 0,01 (**) e 0,05 (*) de probabilidade; (ns) não significativo; CV - coeficiente de variação.

Analisando-se altura das mudas de melancia (Tabela 5) verifica-se uma interação significativa entre os diferentes substratos e águas disponíveis. Quando comparados com a testemunha (100\% solo) e com $100 \%$ da água disponível, os maiores valores em altura da planta foram obtidos nos substratos constituídos com adição de matéria orgânica devido a matéria orgânica ser fonte de nutrientes essenciais às plantas e proporcionar melhoria na infiltração e retenção de água no solo (MOREIRA et al., 2011; SANTOS et al., 2011).
Quando o solo estava na capacidade de campo, com ótimas condições de água para a planta (100\% da água disponível no solo para as plantas), com exceção do substrato $75 \%$ Solo $+25 \%$ Esterco bovino, que teve a menor altura, não houve diferença significativa entre os substratos e suas concentrações. Com menores conteúdos de água no solo (50\% da água disponível no solo para as plantas) praticamente não houve diferença entre os tratamentos de substratos, aparentemente devido a que o conteúdo de água afetou mais o crescimento que a natureza do substrato. 
Observa-se que quando o solo estava com 50\% da água disponível para as plantas a altura média das mudas foi menor que quando o solo estava com $100 \%$ da água disponível para as plantas, 3,85 e 3,98 cm, respectivamente.

Tabela 5. Altura de mudas de melancia cv. Citrulluslunatus (cm) sob diferentes substratos e níveis de água disponíveis no solo

\begin{tabular}{lcc}
\hline \multicolumn{1}{c}{ Substratos } & \multicolumn{2}{c}{ Lâminas de irrigação } \\
\cline { 2 - 3 } & $\mathbf{5 0 \%}$ ADS & $\mathbf{1 0 0 \%}$ ADS \\
\hline $\mathrm{S}_{1}=100 \%$ Solo & 4,07 a A & 3,71 bc A \\
$\mathrm{S}_{2}=75 \%$ Solo + 25\% Esterco bovino & 4,00 a A & 3,20 c B \\
$\mathrm{S}_{3}=75 \%$ solo + 25\% Húmus de minhoca & 3,75 a B & 4,39 a A \\
$S_{4}=50 \%$ solo + 50\% Esterco bovino & 4,04 a A & 3,95 ab A \\
$S_{5}=50 \%$ solo + 50\% Húmus de minhoca & 3,75 a B & 4,19 a A \\
$S_{6}=25 \%$ Solo + 75\% Esterco bovino & 4,04 a A & 3,98 ab A \\
$S_{7}=25 \%$ Solo + 75\% Húmus de minhoca & 3,30 b B & \multicolumn{2}{c}{ 6,54 a A } \\
\hline CV (\%) & \multicolumn{2}{c}{0,56 a } \\
\hline DMS (5\%) Linhas & \multicolumn{2}{c}{0,36 A } \\
\hline DMS (5\%) colunas
\end{tabular}

Médias seguidas de mesma letra, minúscula na coluna e maiúscula na linha não diferem pelo teste de Tukey (P>0,05), ADS= água disponível no solo.

A alturas das mudas obtidas na presente pesquisa com esterco bovino foram inferiores as encontradas por Silvaet al. (2009) e Duarte et al. (2010), que observaram maiores alturas em mudas de melancia cv. Citrulluslunatus $(6,52 \mathrm{~cm})$ em substratos com esterco bovino e solo (1:1).O desdobramento da interação substrato versus água disponível para o diâmetro do caule das mudas mostra resultados semelhantes aos encontrados para a altura das mudas (Tabela 6). Quando o solo estava na capacidade de campo, com ótimas condições de água para a planta (100\% da água disponível no solo para as plantas), com exceção do substrato $\mathrm{S}_{6}$, que teve o menor diâmetro do caule das mudas, não houve diferença significativa entre os substratos.

Quando o solo estava com 50\% da água disponível para as plantas o diâmetro médio do caule das mudas foi menor que quando o solo estava com $100 \%$ da água disponível para as plantas, excetuando a testemunha.

Tabela 6. Diâmetro caulinar de mudas de melancia cv. Citrulluslunatussob diferentes substratos e níveis de água disponíveis no solo

\begin{tabular}{lcc}
\hline \multicolumn{1}{c}{ Substratos } & \multicolumn{2}{c}{ Lâminas de irrigação } \\
\cline { 2 - 3 } & $\mathbf{5 0 \%}$ ADS & $\mathbf{1 0 0 \%}$ ADS \\
\hline $\mathrm{S}_{1}=100 \%$ Solo & 3,61 a A & 3,65 c A \\
$\mathrm{S}_{2}=75 \%$ Solo + 25\% Esterco bovino & 3,92 a A & 3,65 bc A \\
$\mathrm{S}_{3}=75 \%$ solo + 25\% Húmus de minhoca & 3,78 a B & 4,49 a A \\
$\mathrm{S}_{4}=50 \%$ solo + 50\% Esterco bovino & 3,91 a A & 4,16 ab A \\
$S_{5}=50 \%$ solo + 50\% Húmus de minhoca & 3,90 a B & 4,61 a A \\
$S_{6}=25 \%$ Solo + 75\% Esterco bovino & 3,50 a B & 4,32 ab A \\
$S_{7}=25 \%$ Solo + 75\% Húmus de minhoca & 3,62 a B & 4,77 a A \\
\hline CV (\%) & \multicolumn{2}{c}{9,43} \\
\hline DMS (5\%) Linhas & \multicolumn{3}{c}{0,82} \\
\hline DMS (5\%) colunas
\end{tabular}

Médias seguidas de mesma letra, minúscula na coluna e maiúscula na linha não diferem pelo teste de Tukey (P>0,05), ADS= água disponível no solo.

Mesquita et al. (2012) indicam que quando há restrição hídrica ocorre, também, redução do crescimento da planta, devido à redução na tensão matricial 
da água no solo, provocando queda no consumo hídrico com reflexos negativos no diâmetro caulinar das plantas.

Ao analisar o desdobramento da interação substrato versus água disponível para a massa seca da parte aérea (Tabela
7), ao igual que para o diâmetro caulinar, observa-se, em geral, um aumento desta com o incremento dos conteúdos de matéria orgânica nos substratos, sendo que os maiores valores foram encontrados com os substratos formados com húmus de minhoca.

Tabela 7. Massa seca da parte aérea de mudas de melancia cv. Citrulluslunatus(g/planta) sob diferentes substratos e níveis de água disponíveis no solo

\begin{tabular}{|c|c|c|}
\hline \multirow{2}{*}{ Substratos } & \multicolumn{2}{|c|}{ Lâminas de irrigação } \\
\hline & $50 \%$ ADS (1) & $100 \%$ ADS (2) \\
\hline$S_{1}=100 \%$ Solo & 0,22 e $A$ & 0,27 e $\mathrm{A}$ \\
\hline $\mathrm{S}_{2}=75 \%$ Solo $+25 \%$ Esterco bovino & 0,29 de $A$ & 0,29 e $A$ \\
\hline $\mathrm{S}_{3}=75 \%$ solo $+25 \%$ Húmus & 0,32 cd B & 0,39 cd A \\
\hline $\mathrm{S}_{4}=50 \%$ solo $+50 \%$ Esterco bovino & 0,35 bc $\mathrm{B}$ & 0,41 cd $A$ \\
\hline $\mathrm{S}_{5}=50 \%$ solo $+50 \%$ Húmus & $0,41 \mathrm{ab} A$ & 0,45 с A \\
\hline $\mathrm{S}_{6}=25 \%$ Solo $+75 \%$ Esterco bovino & 0,39 bc $\mathrm{B}$ & $0,51 \mathrm{~b} \mathrm{~A}$ \\
\hline$S_{7}=25 \%$ Solo $+75 \%$ Húmus & 0,46 а B & 0,66 a A \\
\hline CV (\%) & \multicolumn{2}{|c|}{9,82} \\
\hline DMS (5\%) Linhas & \multicolumn{2}{|c|}{0,08} \\
\hline DMS (5\%) colunas & \multicolumn{2}{|c|}{0,05} \\
\hline
\end{tabular}

Médias seguidas de mesma letra, minúscula na coluna e maiúscula na linha não diferem pelo teste de Tukey (P>0,05), ADS= água disponível no solo, DMS = Diferença mínima significativa.

Resultados semelhantes foram encontrados por Campanharo et al. (2006) e Oliveira et al. (2006), que observaram maiores massas secas de mudas de tomateiro, Berinjela e pimenta onde se verificaram que os substratos formados a base de insumo proporcionaram maiores massas da parte aérea.

Também se verifica maiores massas secas nas mudas de melancia cultivadas com substratos a base de húmus de minhoca em comparação aos mesmos tratamentos formados com esterco bovino, confirmando que o esterco bovino aparentemente precisa de um tempo maior de 20 dias para a disponibilização de nutrientes as plantas, denotando, com isso, a eficiência dessa fonte orgânica na composição de substratos para produção de mudas de melancia, fato também confirmado por Araújo et al. (2015) que observaram maiores peso seco folhas e de caules em mudas de mamoeiro formadas com substratos contendo húmus de minhoca em comparação as mesmas mudas cultivadas com substrato a base de esterco bovino.

A massa seca da parte aérea das mudas de melancia foi maior quando o solo estava com $100 \%$ da água disponível que com 50\% de água disponível no solo, cuja valores médios foram 0,43 g e 0,35 g, respectivamente. Esses dados são similares aos descritos por Tatagiba et al. (2016), em mudas de eucalipto com $100 \%$ e $50 \%$ da disponibilidade hídrica do substrato. Isto pode estar relacionado a deficiência hídrica nos substratos que retarda o crescimento e a produção de fitomassa em mudas. No mesmo raciocínio Doorenbos e Kassam (2000), quando a necessidade hídrica da planta é plenamente satisfeita, existe uma relação direta entre a evapotranspiração e o crescimento, ou seja, evapotranspiração máxima corresponde a crescimento máximo.

No que tange ao efeito aos níveis de água a 100 e $50 \%$ ADS, constatou-se superioridade de $28,46 \%$ na massa seca total das plantas cultivadas nos substratos irrigados com $100 \%$ ADS em comparação a 50\% ADS, com valores médios de 0,67 g e 0,52 g (Tabela 8). A superioridade é resposta do solo mais úmido, quando irrigado com a maior lâmina de água resultando em maior área de contato dos elementos essenciais com a superfície das raízes. Esta situação está coerente com Prado (2008), ao afirmar que o movimento dos 
nutrientes no solo é maior sob condições hídricas adequadas, isto é, disponibilidade em nível suficiente às plantas.

As mudas formadas nos substratos sem deficiência hídrica sobressaíram àquelas cultivadas com estresse hídrico, apresentando maior crescimento e fitomassa seca em mudas de melancia. O déficit hídrico no solo causa redução em sua absorção, e com isso, as células das plantas tem menor pressão de turgor, levando a menor expansão e crescimento (TAIZ; ZEIGER, 2013).

Tabela 8. Massa seca total (g planta ${ }^{-1}$ ) de mudas de melancia cv. Citrulluslunatussob substratos e níveis de água disponíveis no solo

\begin{tabular}{|c|c|c|}
\hline \multirow{2}{*}{ Substratos } & \multicolumn{2}{|c|}{ Lâminas de irrigação } \\
\hline & $50 \%$ ADS (1) & $100 \%$ ADS (2) \\
\hline$S_{1}=100 \%$ Solo & $0,28 \mathrm{~d} \mathrm{~A}$ & 0,32 e $A$ \\
\hline $\mathrm{S}_{2}=75 \%$ Solo $+25 \%$ Esterco bovino & 0,39 с A & 0,40 e $A$ \\
\hline$S_{3}=75 \%$ solo $+25 \%$ Húmus & 0,40 с B & $0,56 \mathrm{~d} A$ \\
\hline $\mathrm{S}_{4}=50 \%$ solo $+50 \%$ Esterco bovino & $0,58 \mathrm{~b}$ B & 0,72 с A \\
\hline $\mathrm{S}_{5}=50 \%$ solo $+50 \%$ Húmus & $0,63 \mathrm{~b}$ B & 0,78 bc $\mathrm{A}$ \\
\hline $\mathrm{S}_{6}=25 \%$ Solo $+75 \%$ Esterco bovino & $0,63 \mathrm{~b} B$ & 0,86 b A \\
\hline$S_{7}=25 \%$ Solo $+75 \%$ Húmus & 0,75 a B & 1,07 a $\mathrm{A}$ \\
\hline $\mathrm{CV}(\%)$ & \multicolumn{2}{|c|}{6,76} \\
\hline DMS (5\%) Linhas & \multicolumn{2}{|c|}{0,11} \\
\hline DMS (5\%) colunas & \multicolumn{2}{|c|}{0,06} \\
\hline
\end{tabular}

Médias seguidas de mesma letra, minúscula na coluna e maiúscula na linha não diferem pelo teste de Tukey $(\mathrm{P}>0,05)$, ADS= água disponível no solo.

Com relação os substratos, maiores pesos foram observados nos substratos $\mathrm{S}_{6}$ e $\mathrm{S}_{7}$, contendo $75 \%$ de matéria orgânica e $25 \%$ de solo. Isto está relacionado à eficiência da matéria orgânica na retenção de água, e após a mineralização, aumenta a disponibilidade dos nutrientes essenciais às plantas, o que proporciona maior produção de biomassa, fato confirmado por Araújo et al. (2017) em mudas de paricá.
Em geral, as mudas de melancia quando semeadas no substrato solo + húmus de minhoca apresentaram um Índice de Dickson maior que quando semeadas no substrato com esterco bovino. O maior Índice de Dickson $(0,42)$ foi obtido no solo com $100 \%$ de água disponível no substrato formado por $25 \%$ de solo $+75 \%$ de húmus de minhoca. Com $50 \%$ de água disponível o maior índice $(0,30)$ também foi obtido no substrato com $25 \%$ de solo $+75 \%$ de húmus de minhoca (Tabela 9).

Tabela 9. Índices de qualidade de Dickson (IQD) em mudas de melancia Citrulluslunatus sob diferentes substratos e níveis de água disponíveis no solo

\begin{tabular}{|c|c|c|}
\hline \multirow{2}{*}{ Substratos } & \multicolumn{2}{|c|}{ Lâminas de irrigação } \\
\hline & $50 \%$ ADS (1) & $100 \%$ ADS (2) \\
\hline $\mathrm{S}_{1}=100 \%$ Solo & 0,06 с A & $0,06 \mathrm{~d} A$ \\
\hline $\mathrm{S}_{2}=75 \%$ Solo $+25 \%$ Esterco bovino & 0,11 с A & $0,11 \mathrm{~cd} A$ \\
\hline$S_{3}=75 \%$ solo $+25 \%$ Húmus de minhoca & 0,08 с В & 0,17 с A \\
\hline $\mathrm{S}_{4}=50 \%$ solo $+50 \%$ Esterco bovino & 0,22 b B & $0,32 \mathrm{~b} \mathrm{~A}$ \\
\hline$S_{5}=50 \%$ solo $+50 \%$ Húmus de minhoca & 0,22 b B & $0,34 \mathrm{~b} \mathrm{~A}$ \\
\hline$S_{6}=25 \%$ Solo $+75 \%$ Esterco bovino & 0,23 b B & $0,37 \mathrm{ab} A$ \\
\hline$S_{7}=25 \%$ Solo $+75 \%$ Húmus de minhoca & 0,30 a $\mathrm{B}$ & 0,42 a $A$ \\
\hline CV $(\%)$ & \multicolumn{2}{|c|}{13,85} \\
\hline DMS (5\%) Linhas & \multicolumn{2}{|c|}{0,06} \\
\hline DMS (5\%) colunas & \multicolumn{2}{|c|}{0,04} \\
\hline
\end{tabular}

Médias seguidas de mesma letra, minúscula na coluna e maiúscula na linha não diferem pelo teste de Tukey $(\mathrm{P}>0,05)$, ADS= água disponível no solo. 
O Índice de qualidade de Dickson (IQD) é um bom indicador de qualidade de mudas de melancia, pois considera diversas características da muda, especialmente as produções de biomassa (MSPA, MSSR e MST) (OLIVEIRA et al. (2015).

O fato de que para ambos os conteúdos de água do solo as mudas produziram os maiores índices de Dickson mostra novamente a superioridade do húmus de minhoca em comparação ao esterco bovino, promovendo plantas com maiores biomassas e com maior IQD. Ao analisar, os substratos com a mesma percentagem de matéria orgânica, $S_{6}$ e $S_{7}$, observa-se melhor eficiência do esterco bovino na retenção de água em comparação ao húmus de minhoca com superioridade de $79,39 \%$ e $81,67 \%$ com valores de (296 e $371 \mathrm{ml}$ ) e (531 e $674 \mathrm{ml}$ ) para os substratos irrigados com $50 \%$ e $100 \%$ da água disponível do solo, respectivamente. A maior retenção de água nos substratos formados com esterco bovino pode estar relacionada à proporção entre macro e microporos nos substratos, pois de acordo com
Guerrini e Trigueiro (2004), a quantidade e a qualidade de poros determinam a distribuição de sólidos, água e ar nos substratos.

Wendlinget al.(2007), indicam que a porosidade total do substrato é maior no húmus de minhoca que no esterco de bovino, o que resulta numa maior capacidade de retenção de água do húmus de minhoca.

$\mathrm{O}$ substrato $\mathrm{S}_{1}$ foi estatisticamente diferente dos demais substratos para o nível de $50 \%$ ADS e igual ao substrato $\mathrm{S}_{2}$ para o nível de $100 \%$. Com relação às lâminas diferiu estatisticamente, independentemente do insumo orgânico, divergindo dos resultados obtidos por Silva et al. (2004), que a eficiência do uso da água não variou com o regime hídrico, indicando ser uma característica das espécies. As mudas de melancia obtiveram maior eficiência do uso da água à medida que aumentou a percentagem de matéria orgânica no substrato, obtendo maiores eficiências nos substratos $\mathrm{S}_{6}$ e $\mathrm{S}_{7}$, cujos valores foram de (2,13 e $\left.2,03 \mathrm{~g} \mathrm{ml}^{-1}\right)$ e $\left(1,62\right.$ e $\left.1,58 \mathrm{~g} \mathrm{ml}^{-1}\right)$ para $50 \%$ e 100\% ADS, (Tabela 10).

Tabela 10. Eficiência do uso da água $\left(\mathrm{g} \mathrm{ml}^{-1}\right)$ em mudas de melancia cv. Citrulluslunatussob substratos e água disponível no solo

\begin{tabular}{|c|c|c|}
\hline \multirow{2}{*}{ Substratos } & \multicolumn{2}{|c|}{ Lâminas de irrigação } \\
\hline & $50 \%$ ADS (1) & $100 \%$ ADS (2) \\
\hline $\mathrm{S}_{1}=100 \%$ Solo & $0,69 \mathrm{~d} \mathrm{~A}$ & $0,44 \mathrm{~d} \mathrm{~B}$ \\
\hline$S_{2}=75 \%$ Solo $+25 \%$ Esterco bovino & 1,11 с A & 0,62 cd B \\
\hline $\mathrm{S}_{3}=75 \%$ solo $+25 \%$ Húmus & 1,04 с A & 0,81 с В \\
\hline $\mathrm{S}_{4}=50 \%$ solo $+50 \%$ Esterco bovino & 1,66 b A & 1,14 b B \\
\hline$S_{5}=50 \%$ solo $+50 \%$ Húmus & $1,58 \mathrm{~b} \mathrm{~A}$ & 1,07 b B \\
\hline $\mathrm{S}_{6}=25 \%$ Solo $+75 \%$ Esterco bovino & 2,13 a $\mathrm{A}$ & 1,62 a B \\
\hline$S_{7}=25 \%$ Solo $+75 \%$ Húmus & 2,03 a $\mathrm{A}$ & 1,58 a B \\
\hline CV (\%) & \multicolumn{2}{|c|}{7,58} \\
\hline DMS (5\%) Linhas & \multicolumn{2}{|c|}{0,21} \\
\hline DMS (5\%) colunas & \multicolumn{2}{|c|}{0,14} \\
\hline
\end{tabular}

Médias seguidas de mesma letra, minúscula na coluna e maiúscula na linha não diferem pelo teste de Tukey $(\mathrm{P}>0,05)$, ADS= água disponível no solo.

A máxima eficiência do uso da água $\left(2,13 \mathrm{~g} \mathrm{ml}^{-1}\right)$ compreendeu o menor volume de água aplicada $(296 \mathrm{ml})$ para o substrato $\mathrm{S}_{6}$ submetido a $50 \%$ de água disponível no solo, indicando que mudas nutricionalmente adequadas apresentam menores necessidades hídricas. Apesar do nível de 50\% água disponível no solo (ADS) propiciar os maiores valores de eficiência de uso da água, observa- se uma redução de 36,50\% na produção de matéria seca total das mudas de melancia, quando comparada com ao mesmo tratamento com $100 \%$ de ADS, cuja valores foram 0,63 e 0,86 g (Tabela 8).

Pereira et al. (2012) afirmam que mudas que apresentam maior eficiência do uso da água são de suma importância quando se fala em economia dos recursos hídricos, pois as 
mesmas possibilitam um rendimento maior por $\mathrm{m}^{3}$ de água. Resultados semelhantes foram constatados por Silva et al. (2013) que observaram maiores eficiência do uso da água nos tratamentos com menores reposições de 25 e $50 \%$ ETc e 50 e $70 \%$ ECA, respectivamente. Tais diferenças podem ser causadas pela baixa tolerância de mudas de melancia ao déficit hídrico, o que leva esta cultura a perdas crescentes de crescimento e fitomassa seca, reduzindo assim a EUA.

\section{CONCLUSÕES}

As melhores mudas de melancia foram formadas nos substratos contendo $25 \%$ de solo e 75\% matéria orgânica;

O esterco bovino foi mais eficiente na retenção e eficiência do uso da água no substrato em comparação aos húmus de minhoca;

A redução de $100 \%$ para $50 \%$ água disponível no substrato afetou negativamente a produção de mudas de melancia;

As plantas submetidas ao déficit hídrico no solo apresentaram melhor eficiência do uso da água em comparação àquelas formadas com $100 \%$ de água disponível no solo.

\section{REFERÊNCIAS}

ALFENAS, A.C.; ZAUZA, E.A.V.; MAFIA, R.G.; ASSIS, T. F. Clonagem e doenças do eucalipto.2ed. Viçosa: UFV, 2009. p.500.

ALVARENGA, M.A.R.; REZENDE, G.M. Cultura da melancia. Lavras: UFLA, 2002.p.133.

ARAÚJO, E.B.G.; ALMEIDA, L.L.S.; FERNANDES, F.; SÁ, F.V.S.; NOBRE, R.G.; PAIVA, E.P.P.; MESQUITA, E.F.M.; PORTELA, J.C. P. Fontes e doses de matéria orgânica na produção de mudas de mamoeiro. Revista Agrotec, v. 36, n. 1, p. 264-272, 2015.
ARAÚJO, E.F.;AGUIAR, A.S.; ARAUCO, A.M.S.; GONÇALVES, E.O.;ALMEIDA, K.N. S. Crescimento e qualidade de mudas de paricá produzidas em substratos à base de resíduos orgânicos. Revista Nativa, v. 5, n. 1, p. 16-23, 2017.

CAMPANHARO, M.; RODRIGUES, J.J.V.; LIRA JÚNIOR, M.A.; ESPINDULA, M.C.; COSTA, J.V.T. Características físicas de diferentes substratos para produção de mudas de tomateiro. Caatinga, v.19, n.2, p.140-145, 2006.

DICKSON, A.; LEAF, A.L.; HOSNER, J.F. Quality appraisal of white spruce and white pine seedling stock in nurseries.Forest Chronicle, v. 36, n. 1, p.10-13, 1960.

DOORENBOS, J.; KASSAM, A.H.Efeitos da água no rendimento das culturas. 33 vol. Campina Grande:UFCG/FAO:Irrigação e Drenagem,2000. p.221.

DUARTE, A.K.A; CARDOSO, M.O; FIGUEIREDO, L. Crescimento e macronutrientes em mudas de melancia com doses de adubo orgânico. 2010. Horticultura Brasileira, v. 28, n.2, S1633-S1638, 2010.

EMBRAPA. Centro Nacional de Pesquisa de Solos. Manual de métodos de análisedo solo. 3 ed. Rio de Janeiro: EMBRAPA, 2011. 230 p. (Embrapa - CNPS. Documentos, 132).

EMBRAPA. Centro Nacional de Pesquisa de Solos. Sistema Brasileiro de Classificação de Solos. 3. ed. Brasília: Embrapa Solos, 2013. 353p.

FERREIRA, D. F. Sisvar: a computerstatisticalanalysis system. Ciência e Agrotecnologia, v. 35, n.6, p. 1039-1042, 2011.

FILGUEIRA, A.R.F. Novo Manual de Olericultura: Agrotecnologia moderna na produção e comercialização de hortaliças. 3 ed. Viçosa: Ed. UFV. 2007. 412p 
FILGUEIRAS, L. M. B.; BARBOSA, F. M.; MELO, A. S.; FERNADES, P. D.; VIDAL, M. S.; BALDANI, J. I.; MENESES, C.H.S.G. Inoculação de gluconacetobacterdiazotrophicus e seu efeito no desenvolvimento de plantas de arroz vermelho. Biofar: Revista de Biologia e Farmácia, v. 10, n. 2, p. 86-101, 2014.

GOMES JUNIOR, S.F.; CHAVES, M.C.C.; PEREIRA, E.R.; MELLO, J.C.C.B. S.; LIMA, G.B. A. Integraçãode métodos multicritério na busca da sustentabilidade agrícola para a produção de tomates no município de São José de Ubá - RJ. Pesquisa Operacional, v. 31, n. 1, p.157 -171, 2011.

GUERRINI, I.A.; TRIGUEIRO, M. Atributos físicos e químicos de substratos compostos por biossólidos e casca de arroz carbonizada. Revista Brasileira Ciência Do Solo, v. 28, n. 6, p.1069-1076, 2004.

MAGGIONI, M.S.; ROSA, C.B.C.J.; ROSA JUNIOR, E.J.; SILVA, E.F.; ROSA, Y.B.C.J.; SCALON, S.P.Q.; VASCONCELOS, A.A. Development of basill seedlings (Ocimumbasilicum L.) in different density and type of substrates and trays. Revista Brasileira de Plantas Medicinais, v. 16, n. 1, p. 10 - 17, 2014.

MESQUITA, E.F; CHAVES, L.H.G; FREITAS, B.V.; SILVA, G.A.; SOUSA, M.V.R; ANDRADE, R. Produção de mudas de mamoeiro em função de substratos contendo esterco bovino e volumes de recipientes. Revista Brasileira de Ciências Agrárias, v.7, n.1, p. 58-65, 2012.

MOREIRA, R.A.; RAMOS, J.D.; ARAUJO, N.A.; MARQUES, V.B.Produção e qualidade de frutos de pitaia-vermelha com adubação orgânica e granulado bioclástico. Revista Brasileira de Fruticultura, v. Especial, p.762-766, 2011.

OLIVEIRA, A.M.; COSTA, E.; REGO, N.H.; LUQUI, L.L.; KUSANO, D.M.; OLIVEIRA, E.P. Produção de mudas de melancia em diferentes ambientes e de frutos a campo. Revista Ceres, v. 62, n. 1, p. 87-92, 2015.

OLIVEIRA, M.K.T.; OLIVEIRA, F. A; MEDEIROS, J. F; LIMA, C.J.G.S.; GALVÃO, D. C.avaliação de substratos orgânicos na produção de mudas deberinjela e pimenta. Revista Verde de Agroecologia e Desenvolvimento Sustentável, v.1, n.2, p. 2432, 2006.

PEREIRA， D.C.; GRUTZMACHER, P.; BERNARDI, F.H.; MALLMANN, L.S.; COSTA, L. A.M.; COSTA, M. S. S.M. Produção de mudas de almeirão e cultivo no campo, em sistema agroecológico. Revista Brasileira de Engenharia Agrícola e Ambiental, v.16, n.10, p.1100-1106, 2012.

PRADO, R.M. Nutrição de plantas. São Paulo: UNESP, 2008. 407p.

REGO, J.L.; OLIVEIRA, E.L.L.; CHAVES, A.F.; ARAÚJO, A.P.B.; BEZERRA, F.M.L.; SANTOS, A.B.; MOTA,S. Uso de esgoto doméstico tratado na irrigação da cultura da melancia. Revista Brasileira de Engenharia Agrícola e Ambiental, v. 9, n. 1, p. 155-159, 2005.

SANTOS, P.C.; LOPES, L.C.; FREITAS,S.J.; SOUSA, L.B.; CARVALHO, A.J. C.Crescimento inicial e teor nutricional do maracujazeiro amarelo submetido à adubação com diferentes fontes nitrogenadas. Revista Brasileira de Fruticultura, v. Especial, p.722-728, 2011.

SCHMITZ, J.A.K.; SOUZA, P.V.D.; KÄMPF, A.N. Propriedades químicas e físicas de substratos de origem mineral e orgânica para o cultivo de mudas em recipientes. Ciência Rural, v. 32, n. 6, p.937-944, 2002.

SILVA, A.O.; SILVA, E.F.F.; KLAR, A.E. Eficiência de uso da água em cultivares de beterraba submetidas a diferentes tensões da água no solo. Water Resources and Irrigation Management, v.2, n.1, p.2736, 2013. 
SILVA, E.C.; COSTA, C.C.; SANTANA, J.B.L.; MONTEIRO, R.F.; FERREIRA, E.F.; SILVA, A.S. Avaliação de diferentes tipos de substratos na produção de mudas de melancia. Horticultura brasileira, v. 27, n. 2, p. 142146, 2009.

SILVA, W.; SEDIYAMA, T.; SILVA, A.A.; CARDOSO, A.A.; índice de consumo e eficiência do uso da água em eucalipto, submetido a diferentes teores de água em convivência com braquiária. Floresta, v. 34, n. 3, p. 325-335, 2004.

TAIZ, L.; ZEIGER, E. Fisiologia vegetal. Porto Alegre: Artmed,5 Ed. 2013. 918 p.

TATAGIBA, S.D.; PEZZOPANNE, J.E.M.; PINHEIRO, A. A; VINCO, J. S. Crescimento de eucalipto em diferentes condições ambientais. Revista científica, eletrônica, de engenharia florestal, v. 27, n.1, p. 15-29, 2016.

TOSTA, M.S.; LEITE, G.A.; GÓES, G.B.; MEDEIROS, P.V.Q.; TOSTA, P.A. F. Doses e fontes de matéria orgânica no desenvolvimento inicial de mudas de melancia "mickylee". Revista Verde de Agroecologia e Desenvolvimento Sustentável, v.5, n. 2, p. 117-122, 2010.

WENDLING,I; GUASTALA, D.; DEDECEK, R. características físicas e químicas de substratos para produção de mudas de ilexparaguariensisst.hil. Revista Árvore, v.31, n.2, p.209-220, 2007. 